\title{
Duração do ciclo de desenvolvimento de cultivares de arroz em função da emissão de folhas no colmo principal
}

\author{
Duration of developmental cycle of rice cultivars as a function of main stem leaf appearance
}

\author{
Nereu Augusto Streck ${ }^{1}$ Leosane Cristina Bosco ${ }^{2}$ Simone Michelon $^{3}$ Lidiane Cristine Walter $^{2}$ \\ Elio Marcolin ${ }^{4}$
}

\section{RESUMO}

Uma das metas do melhoramento genético de arroz no Sul do Brasil ao longo dos últimos 40 anos foi modificar a duração do ciclo de desenvolvimento das cultivares. Em geral, o ciclo de desenvolvimento foi encurtado, com o objetivo de aumentar a competição com o arroz vermelho, a principal espécie competidora nas lavouras orizícolas. O objetivo deste estudo foi determinar a relação da duração do ciclo de desenvolvimento de arroz com o número final de folhas e com a velocidade de aparecimento de folhas no colmo principal. Um experimento de campo foi realizado em Santa Maria, RS, com cinco épocas de semeadura em dois anos agrícolas (2003/2004 e 2004/2005). Foram utilizados sete genótipos de arroz do grupo "indica”, tipo moderno, variando de ciclo superprecoce a tardio: IRGA 421, IRGA 420, IRGA 417, IRGA 416, BRS 7 (TAIM), BR-IRGA 409, EPAGRI 109. A semeadura e o cultivo das plantas ocorreu em baldes de 12 litros enterrados no solo. Em cada cultivar e em cada época foi determinada a duração, em ${ }^{\circ} \mathrm{C}$ dia $\left(\mathrm{Tb}=11^{\circ} \mathrm{C}\right)$, das fases emergência (EM) - aparecimento do colar da folha bandeira (R2) - e R2 - maturação fisiológica (R9) -, o número final de folhas e o filocrono (tempo para aparecimento de duas folhas sucessivas) no colmo principal. Cada $100^{\circ} \mathrm{C}$ dia de aumento na duração da fase EM-R2 deveu-se a um aumento de 0,5 a 0,7 folhas no colmo principal e cada $100^{\circ} \mathrm{C}$ dia de aumento na fase EM-R2 resultou em um aumento de $100^{\circ} \mathrm{C}$ dia no ciclo total EM-R9. Estes resultados indicam que o encurtamento do ciclo total (EM-R9) das cultivares de arroz é devido à diminuição do número final de folhas no colmo principal $e$ não por variação na velocidade de aparecimento das folhas no colmo principal.

Palavras-chave: soma térmica, Oryza sativa L., filocrono, número final de folhas, desenvolvimento vegetal.

\begin{abstract}
One of the goals of rice breeding programs in Southern Brazil during the last 40 years was to modify the developmental cycle of the genotypes. In general, the developmental cycle was shortened in order to increase rice competitons with red rice, a main weed in rice pads. The objective of this study was to determine the relationship between the duration of rice developmental cycle with main stem final leaf number and with main stem leaf appearance rate. A field experiment was carried out in Santa Maria, RS, in five sowing dates in two growing seasons (2003/2004 and 2004/2005). Seven rice genotypes varying from very early to late maturation were used: IRGA 421, IRGA 420, IRGA 417, IRGA 416, BRS 7 (TAIM), BR-IRGA 409, EPAGRI 109. Plants were grown in 12 liter pots buried in the soil. In each cultivar and sowing date, the duration, in ${ }^{\circ} \mathrm{C}$ day $\left(\mathrm{Tb}=11^{\circ} \mathrm{C}\right)$ of emergence (EM) flag leaf colar appearance (R2) and R2 - physiological maturity (R9) phases, the main stem final leaf number and the phyllochron (time interval between the appearance of two successive leaves) were measured. Each $100^{\circ} \mathrm{C}$ day increase in the duration of the EM-R2 phase were due to a 0,5 - 0,7 main stem final leaf number increase and each $100^{\circ} \mathrm{C}$ day increase in the duration of the EM-R2 phase resulted in a $100^{\circ} \mathrm{C}$ day increase in total cycle EM-R9. These results indicate that the shortening of total developmental cycle (EM-R9) of rice is due to a decrease in main stem final leaf number and not due to change in leaf appearance rate.
\end{abstract}

Key words: thermal time, Oryza sativa L., phyllocron, final leaf number, plant development.

\footnotetext{
${ }^{1}$ Departamento de Fitotecnia, Centro de Ciências Rurais (CCR), Universidade Federal de Santa Maria (UFSM), 97105-900, Santa Maria, RS, Brasil. E-mail: nstreck1@smail.ufsm.br. Autor para correspondência.

${ }^{2}$ Curso de graduação em Agronomia, CCR, UFSM.

${ }^{3}$ Programa de Pós-graduação em Agronomia, UFSM, Santa Maria, RS, Brasil.

${ }^{4}$ Estação Experimental do Arroz (EEA), Instituto Rio-Grandense do Arroz (IRGA), Cachoeirinha, RS, Brasil.
} 


\section{INTRODUÇÃO}

O arroz (Oryza sativa L.) é um dos três cereais mais produzidos no mundo (USDA, 2005) e constitui o alimento básico de aproximadamente 2,4 bilhões de pessoas no mundo (LUZZARDI et al., 2005). Conseqüentemente, a pesquisa nesta cultura tem o potencial de afetar o bem-estar de um considerável número de pessoas. No Brasil, são produzidos aproximadamente $1,8 \%$ do total de arroz produzido em nível mundial e aproximadamente $52 \%$ do arroz produzido na América do Sul (AZAMBUJA et al., 2004). No Rio Grande do Sul, a área cultivada com arroz na safra 2004/2005 foi de mais de 1 milhão de hectares e a produtividade média foi de $6,11 \mathrm{mg} \mathrm{ha}^{-1}$ (IRGA, 2005).

O ciclo de desenvolvimento de gramíneas da emergência até a maturação fisiológica pode ser dividido em duas fases: a fase vegetativa e a fase reprodutiva (COUNCE et al., 2000; STRECK et al., 2003). A fase vegetativa pode ser considerada da emergência até o aparecimento do colar da folha bandeira (COUNCE et al., 2000) ou da emergência até o aparecimento da inflorescência ou antese (STRECK et al., 2003), e a fase reprodutiva pode iniciar no final da fase vegetativa e se estender até a maturação fisiológica (STRECK et al., 2003) ou iniciar na diferenciação da estrutura reprodutiva e terminar na maturação fisiológica (COUNCE et al., 2000). A divisão do ciclo de desenvolvimento em duas fases, baseada no aparecimento de órgãos da planta que são visíveis a olho nu, como em STRECK et al. (2003), tem como vantagens a simplicidade, a fácil identificação a campo, amostragem não destrutiva e o fato da emissão de folhas, um parâmetro de desenvolvimento vegetativo, ocorrer durante a fase vegetativa. A desvantagem é que não é identificada a diferenciação da panícula, um estágio de desenvolvimento importante do ponto de vista do manejo da cultura, pois a segunda parcela da adubação nitrogenada de cobertura é realizada neste momento (SOSBAI, 2003). Esta desvantagem não ocorre na escala de COUNCE et al. (2000).

O ciclo de desenvolvimento do arroz também pode ser dividido em três fases: a fase vegetativa (da emergência até a diferenciação da panícula), a fase reprodutiva (da diferenciação da panícula até a antese) e a fase de enchimento de grãos (da antese até a maturação fisiológica) (GAO et al., 1992; INFELD et al., 1998). Esta última divisão tem a vantagem de ser mais detalhada, o que é importante no manejo da cultura, mas tem como desvantagens exigir uma amostragem destrutiva de plantas e treinamento para visualizar a diferenciação da panícula. Também é uma desvantagem desta divisão do ciclo de desenvolvimento o fato de a emissão de folhas, um parâmetro do desenvolvimento vegetativo, estender-se da fase vegetativa até quase toda a fase reprodutiva, o que tem potencial de causar alguma confusão durante a comunicação entre o pessoal técnico envolvido na cadeia produtiva do arroz.

Uma das metas do melhoramento genético de arroz no Sul do Brasil ao longo dos últimos 40 anos foi modificar a duração do ciclo de desenvolvimento das cultivares (LOPES et al., 2005). Em geral, o ciclo de desenvolvimento foi encurtado. $\mathrm{O}$ encurtamento do ciclo das cultivares modernas de arroz tornou-as mais competitivas com o arroz vermelho, a principal espécie daninha nas lavouras orizícolas. Como resultado deste melhoramento genético, existem disponíveis no mercado cultivares variando de ciclo muito precoce até tardio (SOSBAI, 2003). Outra meta do melhoramento vegetal foi o aumento do rendimento potencial de grãos de arroz, o qual dobrou passando de aproximadamente $6 \mathrm{t} \mathrm{ha} \mathrm{H}^{-1}$ na década de 60 para aproximadamente $12 \mathrm{t} \mathrm{ha}^{-1}$ a partir do início do ano 2000 (LOPES et al., 2005). No entanto, para uma mesma arquitetura de planta, o rendimento de grãos tem, freqüentemente, relação direta com a duração do ciclo de desenvolvimento. Esta relação direta entre rendimento e ciclo está associada com a duração de ambas as fases, da vegetativa (emergência até o aparecimento do colar da folha bandeira ou antese) e da reprodutiva (antese até maturação fisiológica). Uma fase vegetativa longa permite à planta produzir uma área folhar maior durante um período mais longo, o que contribui para aumentar as reservas de fotoassimilados no colmo, que poderão ser translocados para o enchimento de grãos. Uma fase reprodutiva (ou de enchimento de grãos) longa permite um tempo maior de translocação de fotoassimilados para crescimento dos grãos. A fase vegetativa, considerando-se da emergência até o aparecimento do colar da folha bandeira, pode ser modificada pela alteração do número final de folhas, da velocidade de aparecimento das folhas no colmo principal, ou por ambas.

Como o rendimento potencial de grãos de genótipos de arroz dobrou nos últimos 40 anos, enquanto o ciclo de desenvolvimento em geral diminuiu (LOPES et al., 2005), é importante entender como as fases vegetativa e reprodutiva destes genótipos foram alteradas pelo melhoramento, já que rendimento e ciclo estão relacionados. Tal entendimento também pode auxiliar na escolha do genótipo mais apropriado para atingir o potencial de rendimento de grãos em diferentes regiões ecoclimáticas, além de proporcionar uma medida quantitativa do resultado que o melhoramento genético alcançou. LOPES et al. (2005) mostraram que houve tendência de redução da fase 
vegetativa (emergência-floração) dos genótipos desenvolvidos pelo programa de melhoramento do Instituto Rio-Grandense do Arroz (IRGA), de 1961 a 2004. No entanto, não se conhece quais os parâmetros de desenvolvimento (número final de folhas e velocidade de aparecimento das folhas) que são responsáveis pela modificação da fase vegetativa e, portanto, do ciclo de desenvolvimento de genótipos de arroz no Sul do Brasil. Este desconhecimento constituiu o incentivo para este esforço científico.

O objetivo deste estudo foi determinar a relação da duração do ciclo de desenvolvimento de arroz com o número final de folhas e com a velocidade de aparecimento de folhas no colmo principal.

\section{MATERIAL E MÉTODOS}

Um experimento de campo foi realizado em Santa Maria, RS (latitude: 2943'S, longitude: 5343’W e altitude: $95 \mathrm{~m}$ ), com cinco épocas de semeadura e dois anos agrícolas: no ano agrícola 2003/2004, as datas de semeadura foram 01/09/2003, 20/10/2003, 21/11/2003, 05/01/2004 e 29/01/2004 e, no ano agrícola 2004/2005, as datas de semeadura foram 02/09/2004, 07/10/2004, 04/11/2004, 03/12/2004 e 02/03/2005. O clima da região, segundo a classificação de Köppen, é Cfa Subtropical úmido, sem estação seca definida, com verões quentes (MORENO, 1961). O solo do local é uma transição entre a Unidade de Mapeamento São Pedro (Argissolo Vermelho distrófico arênico) e a Unidade de Mapeamento Santa Maria (Alissolo Hipocrômico argilúvico típico) (EMBRAPA,1999).

Foram utilizados sete genótipos de arroz do grupo “indica”, tipo moderno, variando de ciclo muito precoce a tardio: IRGA 421, IRGA 420, IRGA 417, IRGA 416, BRS 7 (TAIM), BR-IRGA 409, EPAGRI 109. A semeadura e o cultivo das plantas ocorreu em baldes de $30 \mathrm{~cm}$ de diâmetro e $26 \mathrm{~cm}$ de altura, com capacidade de 12 litros, enterrados, deixando-se uma borda de $5 \mathrm{~cm}$ acima do nível do solo. O espaçamento entre baldes (centro a centro) foi de $1,5 \mathrm{~m} \times \mathrm{0}, 8 \mathrm{~m}$. Foram semeadas 30 sementes por balde e, quando as plantas estavam no estágio V3 da escala de COUNCE et al. (2000), foi realizado um raleio, deixando-se 10 plantas/balde. Cinco destas plantas por balde foram etiquetadas com arames coloridos.

O delineamento experimental foi inteiramente casualizado, com quatro repetições (4 baldes/cultivar, em cada época de semeadura). A adubação e o manejo das plantas seguiu as recomendações para o cultivo de arroz irrigado (SOSBAI, 2003). A irrigação foi realizada de modo a manter uma lâmina de água com aproximadamente $5 \mathrm{~cm}$ desde o estádio V3 até o estádio R9 da escala de COUNCE et al. (2000).
A data de emergência (50\% das plantas visíveis acima do nível do solo) foi determinada em cada balde. No colmo principal das cinco plantas etiquetadas por balde, foram quantificados, semanalmente, o número de folhas e o comprimento da última e penúltima folha para cálculo do Estágio de Haun (HS, folhas) com a equação 1 (HAUN, 1973):

$\mathrm{HS}=(\mathrm{NF}-1)+\mathrm{L}_{\mathrm{n}} / \mathrm{L}_{\mathrm{n}-1}$

em que o NF é o número de folhas, $\mathrm{L}_{\mathrm{n}}$ é o comprimento da última folha $(\mathrm{cm})$ e $\mathrm{L}_{\mathrm{n}-1}$ é o comprimento da penúltima folha (cm). No colmo principal destas mesmas plantas etiquetadas, foram ainda contados o número final de folhas, a data do aparecimento do colar da folha bandeira (estádio R2 da escala de COUNCE et al., 2000) e a data da maturação fisiológica (estádio R9 da escala de COUNCE et al., 2000). Para fins deste estudo, considerou-se que a fase vegetativa é da emergência (EM) até R2 e a fase reprodutiva de R2 a R9. Foi feita a média das datas destes estádios de desenvolvimento nas cinco plantas por balde e depois a média das datas dos quatro baldes/cultivar.

As temperaturas mínimas e máximas diárias do ar, durante os períodos experimentais, foram quantificadas em uma estação meteorológica convencional, pertencente ao $8^{\circ}$ Distrito de Meteorologia/ Instituto Nacional de Meteorologia, localizada a aproximadamente 200 metros da área experimental.

A soma térmica diária (STd, ${ }^{\circ} \mathrm{C}$ dia) foi calculada com a equação 2 (GILMORE \& ROGERS, 1958; ARNOLD, 1960):

$\mathrm{STd}=(\mathrm{Tm}-\mathrm{Tb})$. 1dia

em que Tm é a temperatura média diária do ar, calculada pela média aritmética da temperatura máxima e mínima diária do ar, e Tb é a temperatura base para o arroz, que é definida como a temperatura mínima abaixo da qual não há desenvolvimento. Assumiu-se uma $\mathrm{Tb}=11^{\circ} \mathrm{C}$ (INFELD et al., 1998).

A soma térmica acumulada (STa, ${ }^{\circ} \mathrm{C}$ dia) das fases EM-R2 e R2-R9 de cada genótipo foi calculada pelo somatório da soma térmica diária, conforme equação 3:

$\mathrm{STa}=\Sigma \mathrm{STd}$

A velocidade de aparecimento de folhas foi estimada pelo filocrono, definido como o tempo, em ${ }^{\circ} \mathrm{C}$ dia, necessário para aparecimento de uma folha no colmo (SKINNER \& NELSON, 1995; RICKMAN \& 
KLEPPER, 1995; WILHELM \& McMASTER, 1995). Foi realizada uma regressão linear entre HS na haste principal e STa a partir de emergência em cada genótipo (por balde) e época de semeadura. O filocrono foi estimado como sendo o inverso do coeficiente angular da regressão linear entre HS e STa a partir da emergência (KLEPPER et al., 1982; KIRBY, 1995; XUE et al., 2004). Os dados foram analisados segundo um esquema trifatorial (7cultivares x 5 épocas de semeadura x 2 anos agrícolas).

\section{RESULTADOS E DISCUSSÃO}

A análise de variância revelou que foram estatisticamente significativos os efeitos da cultivar (C), época de semeadura (E) e ano (A) das interações duplas C x E, C x A e E x A e da interação tripla C x E x A para as variáveis número final de folhas e filocrono no colmo principal. Os resultados também indicaram que o efeito do fator cultivar foi maior para a variável número final de folhas, enquanto que o efeito do fator época de semeadura foi maior para a variável filocrono. A soma térmica das fases EM-R2 e EM-R9 também variou entre cultivares em uma mesma época e, para uma mesma cultivar, variou entre épocas. Por estes resultados, seria preciso fazer a análise das variáveis dentro de cada cultivar, época de semeadura e ano, ou seja, de todas as combinações da interação tripla. No entanto, optou-se por uma análise conjunta dos dados dentro de cada ano agrícola, similar ao procedimento usado por RODRIGUES et al. (2001), pois o protocolo experimental adotado (cultivares de ciclo distinto semeadas em épocas diferentes) era o mais apropriado para que se tivesse grande diferença de ciclo e número final de folhas e, assim, o objetivo do trabalho pudesse ser alcançado.

Na última época de semeadura do ano agrícola 2003/2004, apenas as plantas da cultivar "IRGA 421" completaram o ciclo de desenvolvimento (atingiram R9) e, na última época de semeadura do ano agrícola 2004/2005, nenhuma cultivar atingiu R9, mas as plantas atingiram R2, e, portanto, foram usadas na análise. Houve variação acentuada de ${ }^{\circ} \mathrm{C}$ dia do ciclo total de desenvolvimento entre as cultivares (Tabela

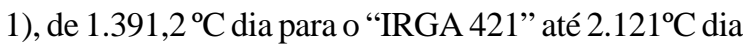
para o “EPAGRI 109”, caracterizando genótipos de ciclo superprecoce a tardio, respectivamente. As cultivares de ciclo precoce e médio (“IRGA 420”, “IRGA 417” e “IRGA 416”) tiveram duração do ciclo total em torno de $1.700^{\circ} \mathrm{C}$ dia e as cultivares médio-tardias ("BR-IRGA 409” e "BRS 7 TAIM”) tiveram a duração do ciclo total em torno de $1.900^{\circ} \mathrm{C}$ dia.
Na figura 1, estão representadas as relações entre a duração do ciclo total (EM-R9) e a duração das fases EM-R2 e R2-R9, entre a duração da fase EM-R2 com o número final de folhas e entre a duração da fase EM-R2 e o filocrono do colmo principal em cada ano agrícola. Os pontos representam a média das cultivares nas diferentes épocas de semeadura em cada ano agrícola.

A duração do ciclo total (EM-R9) de desenvolvimento de cultivares de arroz teve relação linear positiva com a duração da fase vegetativa EMR2 com coeficiente de determinação $\left(\mathrm{r}^{2}\right)$ de 0,87 e 0,90, nos anos agrícolas 2003/2004 e 2004/2005, respectivamente (Figuras 1a e 1e). No entanto, a duração de EM-R9 não teve relação com a duração da fase reprodutiva R2-R9 (Figura 1b, 1f). Estes resultados indicam que a diferença do ciclo total de desenvolvimento das cultivares de arroz é uma função da duração da fase de emissão de folhas, ou seja, quanto mais precoce a cultivar, menor a fase vegetativa e quanto mais tardia, maior a fase vegetativa. Resultados semelhantes foram apresentados em STRECK et al. (2003), que relataram que a duração da fase antese-maturação fisiológica de duas cultivares de trigo de inverno com ciclo total de desenvolvimento distinto foi a mesma. Como o coeficiente angular da relação entre a duração da fase EM-R9 e EM-R2 foi próximo de 1 nos dois anos agrícolas (Figuras 1a e 1e), pode-se interpretar que cada $100^{\circ} \mathrm{C}$ dia de aumento na duração da fase vegetativa (EM-R2) aumenta $100^{\circ} \mathrm{C}$ dia na duração do ciclo total (EM-R9).

A diminuição da fase vegetativa EM-R2 das cultivares mais precoces, por sua vez, ocorreu pela diminuição do número final de folhas no colmo principal, com um $\mathrm{r}^{2}$ de 0,72 e 0,75 nos anos agrícolas 2003/2004 e 2004/2005, respectivamente (Figura 1c, 1g),

Tabela 1 - Graus-dia $\left({ }^{\circ} \mathrm{C}\right.$ dia) do ciclo total de desenvolvimento (EM-R9) de cultivares de arroz. Os valores correspondem à média de várias épocas de semeadura em dois anos agrícolas. EM = emergência, R9 = maturação fisiológica. Santa Maria, RS, 2003-2005.

\begin{tabular}{ll}
\hline Cultivar & ${ }^{\circ} \mathrm{C}$ dia \\
\hline IRGA 421 & $1391,2( \pm 138,6)$ \\
IRGA 420 & $1731,8( \pm 140,3)$ \\
IRGA 417 & $1681,7( \pm 121,5)$ \\
IRGA 416 & $1699,9( \pm 142,2)$ \\
BRS 7 (TAIM) & $1867,0( \pm 194,6)$ \\
BR-IRGA 409 & $1903,4( \pm 204,5)$ \\
EPAGRI 109 & $2121,0( \pm 102,3)$ \\
\hline
\end{tabular}

Valores entre parênteses representam um desvio padrão da média. 

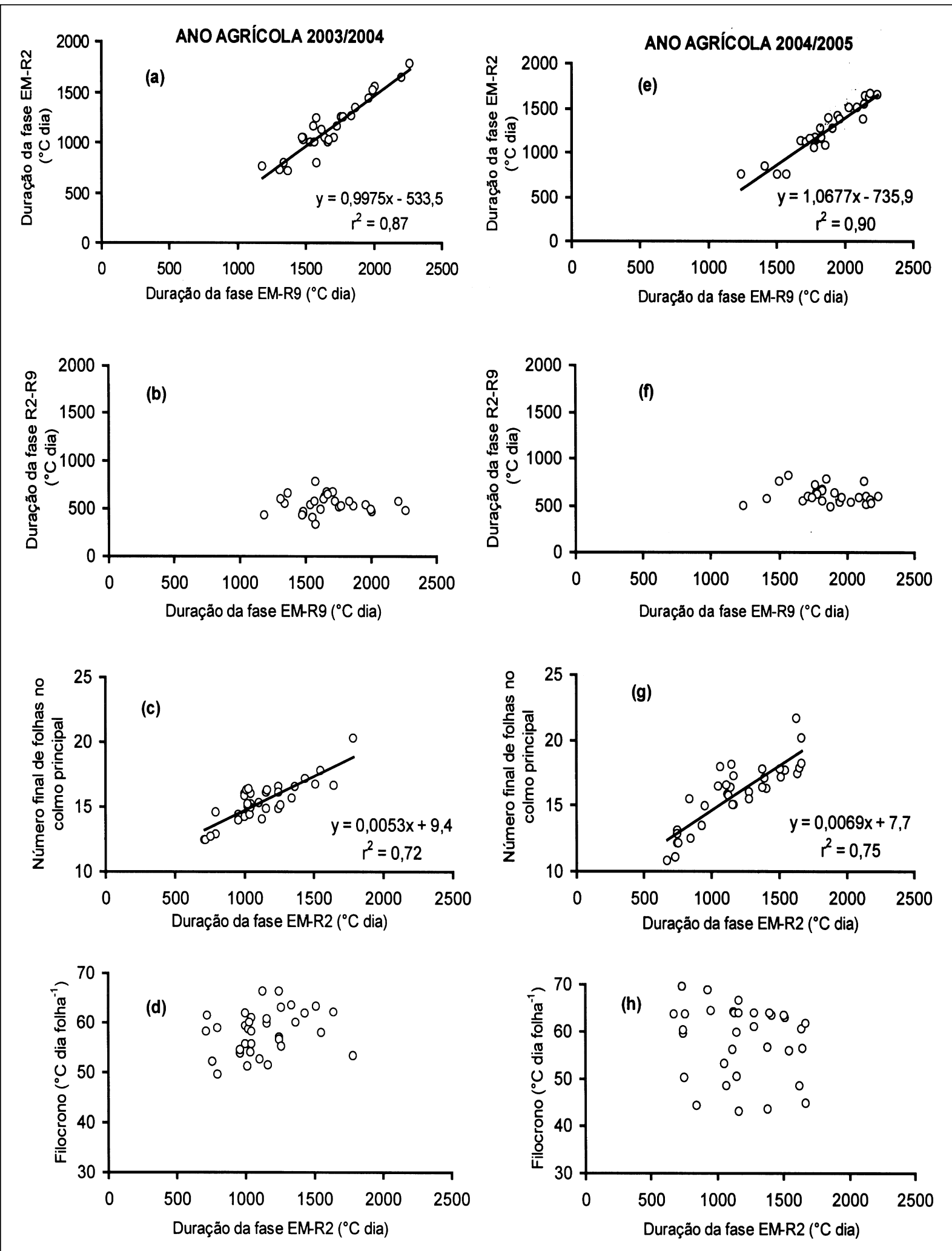

Figura 1 - Relação entre duração da fase EM-R2 e ciclo total EM-R9 (a, e), relação entre duração da fase R2-R9 e ciclo total EM-R9 (b, f), relação entre número final de folhas no colmo principal e duração da fase EM-R2 (c, g) e relação entre filocrono e duração da fase EM-R2 (d, h) de arroz irrigado. Santa Maria, RS, Brasil. EM=emergência, R2=aparecimento do colar da folha bandeira, R9=maturação fisiológica. 
e não por mudanças na velocidade de aparecimento de folhas, já que o filocrono não mostrou relação com a fase EM-R2 (Figuras 1d e 1h). O número final de folhas no colmo principal, nos dois anos agrícolas, variou de 10 a 21 folhas. Esta variação foi devida à variação entre cultivares (quanto mais precoce, menor o número final de folhas) e, para uma mesma cultivar, em função da época de semeadura, com semeaduras feitas mais cedo tendo maior número final de folhas e semeaduras tardias tendo menor número final de folhas. A cultivar de ciclo mais longo (EPAGRI 109) apresentou maior número final de folhas no colmo principal, com um máximo de 21 folhas na primeira época de semeadura, no ano agrícola 2004/2005, enquanto a cultivar de ciclo mais curto (“IRGA 421”) teve o menor número de folhas no colmo principal nas últimas épocas de semeadura, com 10 folhas no ano agrícola 2004/2005. Pelos coeficientes angulares das regressões apresentadas nas figuras $1 \mathrm{c}$ e $1 \mathrm{~g}$, estima-se que cada $100^{\circ} \mathrm{C}$ dia de aumento na duração da fase EM-R2 deve-se a um aumento médio de 0,5-0,7 folhas no colmo principal.

Na figura 2, é apresentada a duração percentual das fases EM-R2 e R2-R9 em relação ao ciclo total (EM-R9) nos dois anos agrícolas. Observase que, nos dois anos, a fase mais longa é a fase EMR2, perfazendo aproximadamente $75 \%$ do ciclo total na cultivar tardia “EPAGRI 109” e na cultivar média-tardia “BR-IRGA 409", diminuindo à medida que o ciclo total diminui, chegando a aproximadamente 55\% do ciclo total na cultivar muito precoce "IRGA 421". Nota-se

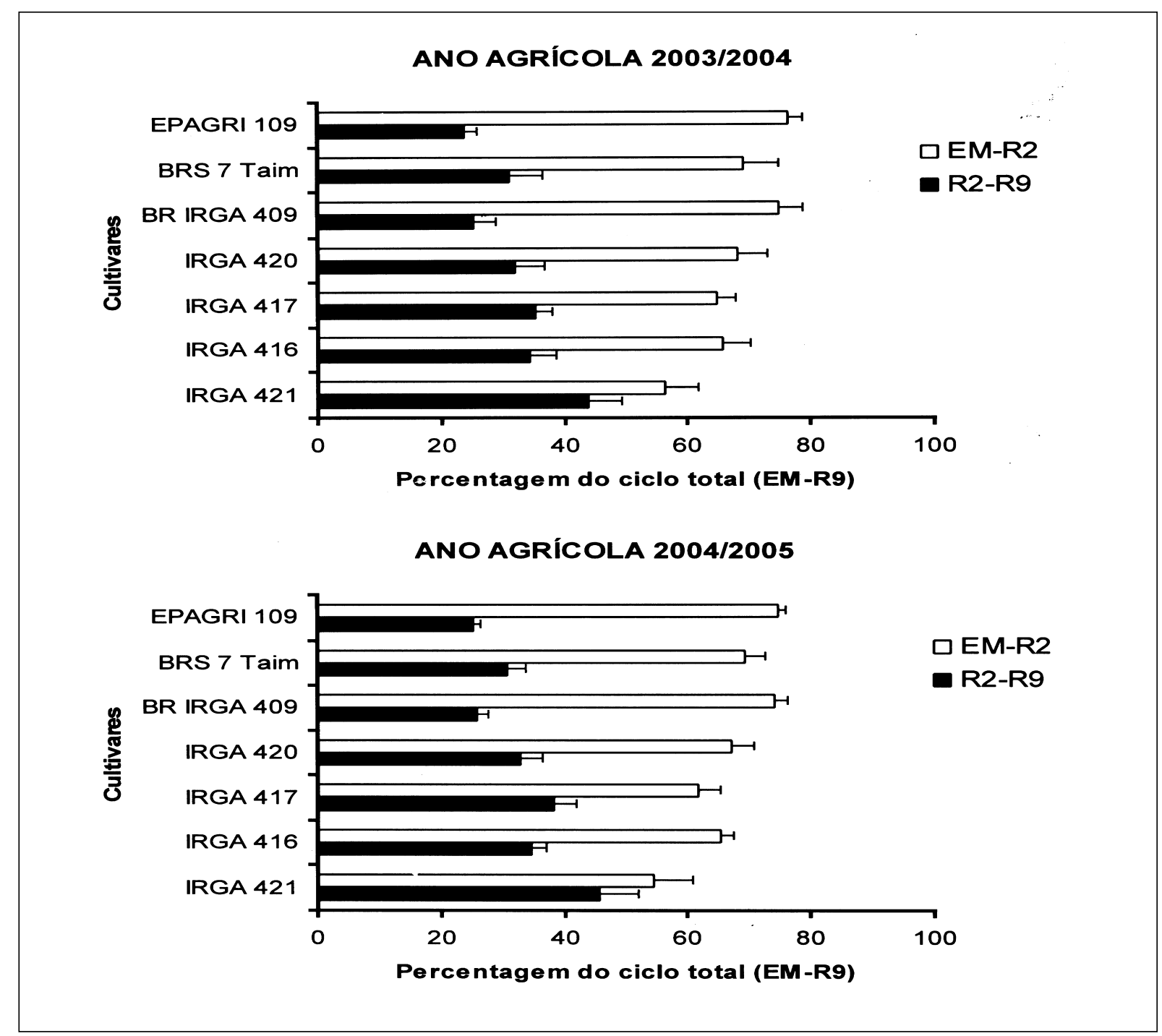

Figura 2 - Duração percentual das fases vegetativa EM-R2 e reprodutiva R2-R9 em relação ao ciclo total EM-R9 de cultivares de arroz irrigado. Santa Maria, RS, 2003-2005. EM=emergência, R2=aparecimento do colar da folha bandeira, R9=maturação fisiológica.

Ciência Rural, v.36, n.4, jul-ago, 2006. 
também na figura 2 que, com exceção da cultivar muito precoce ("IRGA 421"), todas as outras cultivares tiveram a fase EM-R2 correspondendo a mais de $60 \%$ do ciclo total.

Crescimento e desenvolvimento vegetal são processos independentes e inter-relacionados. Enquanto crescimento envolve aumento irreversível de dimensões físicas como área, comprimento, largura, altura, volume ou diâmetro de órgãos, desenvolvimento refere-se a processos envolvendo diferenciação celular e iniciação morfológica e aparecimento de órgãos (HODGES, 1991; STRECK et al., 2003). A caracterização de parâmetros de desenvolvimento durante o ciclo das cultivares de arroz pode ajudar a explicar o ganho de rendimento (parâmetro de crescimento) obtido pelo melhoramento genético. $\mathrm{O}$ aumento de rendimento que o programa de melhoramento do IRGA alcançou nos últimos 40 anos aconteceu mesmo com uma diminuição na fase emergência-floração (LOPES et al., 2005). Os resultados do presente estudo revelaram que a duração da fase reprodutiva R2-R9 é similar entre genótipos de ciclo total EM-R9 distintos (Figuras 1b e 1f). É importante que a fase R2-R9 seja mantida longa para maximizar o enchimento de grãos, o que foi feito pelo melhoramento genético. Como o rendimento das cultivares aumentou (LOPES et al., 2005), resulta que a diminuição da duração da fase EM-R2 não comprometeu o enchimento de grãos. A exceção é a cultivar muito precoce ("IRGA 421"), que tem um rendimento potencial de 3 a $4 \mathrm{mg} \mathrm{ha}^{-1}$ menor do que outras cultivares como "BR-IRGA 409" e "IRGA 417" (MARIOT et al., 2005).

A diminuição do ciclo total de desenvolvimento da "IRGA 421" pelo melhoramento foi muito drástica (Tabela 1) e às custas da diminuição drástica do número de folhas no colmo principal, o qual foi muito baixo, chegando a 10 folhas na última época de semeadura do ano 2004/2005, tendo sempre de 2 a 6 folhas a menos que as outras cultivares nas diferentes épocas. O menor rendimento de grãos potencial da cultivar "IRGA 421” pode ser, portanto, devido à redução do número final de folhas, já que um menor número final de folhas significa uma área foliar menor, a qual permanece fotossintetizando por um período de tempo menor, reduzindo assim a acumulação de reservas no colmo durante a fase EM-R2, que poderão ser translocadas para os grãos. Por isso, a cultivar “IRGA 421” é indicada para situações em que a semeadura das cultivares de maior rendimento potencial não é possível na época recomendada, ou seja, em semeaduras tardias, como, por exemplo, em dezembro no Estado do RS, quando o rendimento desta cultivar é superior ao rendimento das demais cultivares (MARIOT et al., 2005). Nestas situações, a cultivar "IRGA 421" completa rapidamente a fase EM-R2 e a floração ainda não é afetada pelas baixas temperaturas no final do verão e início do outono, o que não acontece com as outras cultivares com semeaduras em dezembro.

\section{AGRADECIMENTOS}

Ao Instituto Rio-Grandense do Arroz (IRGA), pela ajuda financeira no primeiro ano e pelo fornecimento das sementes nos dois anos deste estudo. Ao Programa Institucional de Bolsas de Iniciação Científica do Conselho de Desenvolvimento Científico e Tecnológico (PIBIC/CNPq/ UFSM), pela concessão de bolsa ao pesquisador de iniciação científica (BIC) Bosco. À Coordenação de Aperfeiçoamento de Pessoal de Nível Superior (CAPES), pela concessão de bolsa ao pesquisador de mestrado Michelon. Ao Fundo de Incentivo à Pesquisa e Extensão (FIPE) da UFSM, pela concessão de bolsa ao pesquisador de iniciação científica Walter.

Aos estudantes de Agronomia Isabel Lago, Hamilton Telles Rosa, Gizelli Moiano de Paula, Flávia Kauffman Samboranha e Catia Câmera, pela ajuda na condução do experimento e na coleta dos dados.

\section{REFERÊNCIAS}

ARNOLD, C.Y. Maximum-minimum temperatures as a basis for computing heat units. Proceedings of the American Society for Horticultural Sciences, Boston, v.76, n.1, p.682-692, 1960.

AZAMBUJA, I.H.V. et al. Aspectos socioeconômicos da produção do arroz. In: GOMES, A.S.; MAGALHÃES Jr, A.M. Arroz irrigado no Sul do Brasil. Brasília: Embrapa, 2004. p.23-44.

COUNCE, P. et al. A uniform, objective, and adaptative system for expressing rice development. Crop Science, Madison, v.40, n.2, p.436-443, 2000.

EMBRAPA. Sistema Brasileiro de Classificação de Solos. Brasília: Embrapa produções de informações, 1999. 412p.

GAO, L. et al. Rice clock model - a computer model to simulate rice development. Agricultural and Forest Meteorology, Amsterdam, v.60, n.1, p.1-16, 1992.

GILMORE, E.C. Jr.; ROGERS, J.S. Heat units as a method of measuring maturity in corn. Agronomy Journal, Madison, v.50, n.10, p.611-615, 1958.

HAUN, J.R. Visual quantification of wheat development. Agronomy Journal, Madison, v.65, p.116-119, 1973.

HODGES, T. Predicting crop phenology. Boca Raton: CRC, 1991. 233p.

INFELD, J.A. et al. Temperatura base e graus-dia durante o período vegetativo de três grupos de cultivares de arroz irrigado. Revista Brasileira de Agrometeorologia, Santa Maria, v.6, n.2, p.187-191, 1998. 
IRGA - Instituto Rio Grandense do Arroz. Dados de safra: série histórica da área plantada, produção e rendimento. Capturado em 15 jun 2005. On line. Disponível em: http: www.irga.rs.gov.br/dados.htm.

KIRBY, E.J. Factors affecting rate of leaf emergence in barley and wheat. Crop Science, Madison, v.35, n.1, p.11-19, 1995.

KLEPPER, B. et al. Quantitative characterization of vegetative development in small cereal grains. Agronomy Journal, Madison, v.7, p.780-792, 1982.

LOPES, S.I.G. et al. Avaliação do ganho genético do programa de melhoramento do IRGA no período de 1961 a 2004 . In: CONGRESSO BRASILEIRO DE ARROZ IRRIGADO, 4., 2005, Santa Maria, RS. Anais... Santa Maria: Sociedade Sul-Brasileira de Arroz Irrigado, 2005. V.1, 567p. p.67-69.

LUZZARDI, R. et al. Avaliação preliminar da produtividade em campo e qualidade industrial de híbridos de arroz no Rio Grande do Sul. In: CONGRESSO BRASILEIRO DE ARROZ IRRIGADO, 4., 2005, Santa Maria, RS. Anais... Santa Maria: Sociedade SulBrasileira de Arroz Irrigado, 2005. V.1. 567p. p.70-72.

MARIOT, C.H.P. et al. Influência da época de semeadura no rendimento de grãos de cultivares de arroz irrigado - safras 2003/2004 e 2004/2005. In: CONGRESSO BRASILEIRO DE ARROZ IRRIGADO, 4., 2005, Santa Maria, RS. Anais... Santa Maria: Sociedade Sul-Brasileira de Arroz Irrigado, 2005. V.1, 567p, p.251-253.

MORENO, J.A. Clima do Rio Grande do Sul. Porto Alegre: Secretaria da Agricultura, 1961. 46p.
RICKMAN, R.W.; KLEPPER, B.L. The phyllochron: Where do we go in the future? Crop Science, Madison, v.35, n.1, p.44-49, 1995.

RODRIGUES et al. Resposta quantitativa do florescimento da soja à temperatura e ao fotoperiodo. Pesquisa Agropecuária Brasileira, Brasília, v.36, n.3, p.431-437, 2001.

SKINNER, R.H.; NELSON, C.J. Elongation of the grass leaf and its relationship to the phyllochron. Crop Science, Madison, v.35, n.1, p.4-10, 1995

SOSBAI - Sociedade Sul-Brasileira de Arroz Irrigado. Arroz irrigado: recomendações técnicas para o Sul do Brasil. Itajaí, 2003. 126p.

STRECK, N.A. et al. Improving predictions of developmental stages in winter wheat: A modified Wang and Engel model. Agricultural and Forest Meteorology, Amsterdam v.115, n.3-4, p.139-150, 2003.

USDA [United State Departament of Agriculture]. Wheat, rice, and corn area, yield and production. 2005. Capturado em 15 maio 2005. On line. Disponível em: http: www.fas.usda.gov/psd.

WILHELM, W.W.; McMASTER, G.S. Importance of the phyllochron in studying development and growth in grasses. Crop Science, Madison, v.35, n.1, p.1-3, 1995.

XUE, Q. et al. Predicting leaf appearance in field grown winter wheat: evaluating linear and non-linear models. Ecological Modelling, Amsterdam v.175, p.261-270, 2004. 